\title{
A importância do agronegócio familiar no Brasil
}

\author{
Joaquim J. M. Guilhoto* \\ Fernando G. Silveira** \\ Silvio M. Ichihara*** \\ Carlos R. Azzoni****
}

Resumo: Este trabalho teve por objetivo avaliar o nível de atividade do agronegócio da agricultura familiar no Brasil, para o período de 1995 a 2003. Através dos Modelos de Insumo-Produto foi possível estimar a importância do Produto Interno Bruto do agronegócio familiar no contexto nacional. Concretamente, os resultados demonstram que cerca de 1/3 do agronegócio brasileiro advém da produção agropecuária realizada pelos agricultores familiares, cabendo observar, também, que o desempenho recente da agropecuária familiar e de todo o complexo a ela articulada vem sendo bastante positivo, superando, inclusive, as taxas de crescimento relativas ao segmento patronal.

Palavras-chave: agronegócio familiar, Produto Interno Bruto, Brasil, insumoproduto.

Classificação JEL: Q13, D57, O13

Abstract: This paper presents the results for the familiar activity level of the agricultural agribusiness in the Brazilian economy for the period from

* Professor Titular, FEA - USP, Pesquisador do CNPq. guilhoto@usp.br

** IPEA e Doutorando em Economia, UNICAMP. gaiger@ipea.gov.br

*** Doutorando em Economia Aplicada, ESALQ-USP. smasichi@esalq.usp.br

**** Professor Titular, FEA-USP, Pesquisador do CNPq. cazzoni@usp.br 
1995 to 2003. Using input-output models it was possible to estimate the importance of the Gross Domestic Product of the familiar agribusiness in the national economy. The results show that around 1/3 of the Brazilian agribusiness come from the agricultural production done by the familiar agriculture, it was also noticed that the recent development of the familiar agriculture and of its links has been very positive, suppressing, the growth rates found in the non-familiar segment.

Keywords: Familiar agribusiness, Gross Domestic Product, Brazil, inputoutput.

JEL Classification: Q13, D57, 013

\section{Introdução}

O setor agropecuário familiar faz parte da história do Brasil e da própria humanidade. Sua influência foi reduzida ao longo dos séculos devido ao desenvolvimento tecnológico do próprio setor agropecuário e dos outros setores produtivos da economia. Assim, paulatinamente, o termo familiar tem sido associado a passado, atraso e pouca significância.

Entretanto, o mundo contemporâneo colocou o sistema familiar de produção dentro de um contexto sócio-econômico próprio e delicado, haja vista, que sua importância ganha força quando se questiona o futuro das pessoas que subsistem do campo, a problemática do êxodo rural e, consequentemente, a tensão social decorrente da desigualdade social no campo e nas cidades.

Se por um lado, a agropecuária familiar tem um papel social inquestionável, por outro, sua sobrevivência é incerta. Por si só, este setor produtivo é desorganizado e ineficaz para promover seus próprios interesses.

Muitos setores produtivos são capazes de associar suas empresas a fim de defender interesses comuns, mas no caso do setor agropecuário, a consolidação de grupos que alvejam ideais parecidos é uma tarefa intrincada e às vezes inviável. O grande número de unidades de produção rural diverge em termos de tamanho, capital e tecnologia, tornando as prioridades individuais diferentes. No caso das propriedades de menor porte, o problema é acentuado, dada à diversidade de sistemas e estra- 
tégias produtivas que determinam objetivos difusos, por conseqüência, a força do setor é diluída em grupamentos locais. Associações e cooperativas possibilitam a permanência do sistema familiar em algumas regiões, mas são totalmente inexistentes em outras.

Cabe, então, ao governo e às comunidades a promoção de medidas capazes de alterar os rumos da produção familiar, devido a sua importância estratégica no que se diz respeito ao bem estar geral da sociedade.

A fim de melhorar o direcionamento de políticas públicas, com ênfase no familiar, é, primordialmente, necessário traçar o perfil deste segmento. A delimitação do espaço ocupado por este setor dentro do amplo contexto da economia brasileira pode auxiliar a criação de alternativas que visem à manutenção, ou mesmo, a melhoria da feição familiar, buscando a tão alvejada sustentabilidade deste tipo de ocupação.

Para avaliar com precisão a importância e a complexidade do segmento familiar, deve-se considerar, além da agropecuária propriamente dita, as atividades a montante (antes da fazenda) e a jusante (depois da fazenda). Essas atividades tendem a ser extremamente interdependentes do ponto de vista econômico, social e tecnológico. Portanto, as políticas econômicas e setoriais, de um lado, e as estratégias das entidades representativas dos setores envolvidos, de outro, tenderão a ser mais eficazes sempre que levarem em conta tais interdependências.

No cerne desta questão, este trabalho teve o objetivo de mensurar a importância não apenas da produção agropecuária familiar, mas sim de todo o complexo envolvido - o agronegócio familiar. Mensurou-se a participação do Produto Interno Bruto (PIB) do agronegócio familiar no contexto geral da economia brasileira, delineando sua evolução no período de 1995 a 2003.

Inicialmente, apresenta-se o método empregado na obtenção das estimativas do valor bruto da produção (VPB), referente às propriedades familiares, dentro do horizonte temporal da análise. Posteriormente, são descritos a construção das matrizes de insumo-produto e o modelo usado para mensurar o Produto Interno Bruto (PIB) do agronegócio familiar. Por fim, os resultados são analisados, demonstrando toda a influência exercida pelo segmento familiar. 


\section{Metodologia}

Para atingir os objetivos propostos foram utilizadas bases de dados secundárias provenientes de fontes distintas, sendo que os métodos de análise empregados fundamentam-se nos modelos de insumo produto.

Nesta seção, inicialmente, apresenta-se o método empregado na obtenção das estimativas do valor bruto da produção (VPB), referente às propriedades familiares, dentro do horizonte temporal da análise. Posteriormente, são descritos a construção das matrizes de insumoproduto e o modelo usado para mensurar o Produto Interno Bruto (PIB) do agronegócio familiar.

\subsection{Estimativa da produção familiar - agricultura e pecuária}

A determinação da parcela do PIB do Agronegócio que está vinculada às cadeias produtivas articuladas pela agropecuária familiar depende, primeiramente, do VBP que é gerado pelas unidades de produção familiar.

Através da pesquisa realizada pelo convênio FAO/INCRA ${ }^{1}$ é possível mensurar o VBP dos produtos oriundos da atividade familiar. Entretanto, isto é possível apenas para o ano de 1996. Outras pesquisas realizadas periodicamente pelo Instituto Brasileiro de Geografia e Estatística (IBGE) retratam os sistemas produtivos da agricultura e pecuária. Alguns destes levantamentos podem ser desagregados para vários produtos até o nível municipal, entretanto, não é possível estratificar os dados a fim de definir se a produção é de origem familiar ou não.

Devido à necessidade de se avaliar a produção familiar ao longo dos anos, este trabalho propõe um meio de associação entre os dados disponíveis da pesquisa FAO/INCRA (existentes para um único período) com os recorrentes levantamentos feitos pelo IBGE.

Para esclarecer como esta associação foi realizada e explicar de forma sucinta o cálculo do VPB das atividades familiares faz-se uso do esquema da Figura 2.1.

${ }^{1}$ A pesquisa "Novo Retrato da Agricultura Familiar”, realizada pelo convênio entre o Instituto Nacional de Colonização e Reforma Agrária (INCRA) e a Organização das Nações Unidas para Agricultura e Alimentação (FAO), caracterizou o segmento da agricultura familiar brasileira a partir dos dados do Censo Agropecuário de 1995/96 (INCRA, 2000). 
Figura 2.1 - Esquematização do cálculo das estimativas do VBP da agropecuária familiar

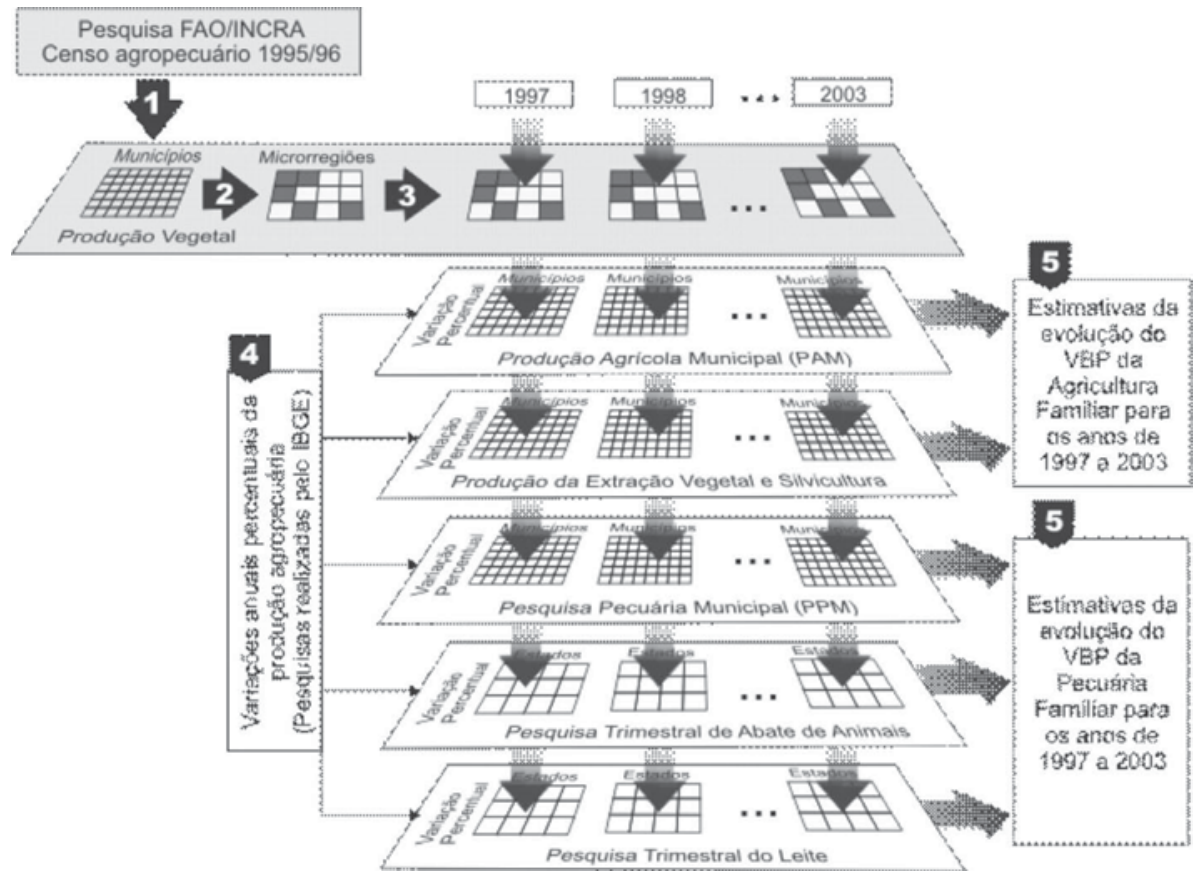

Fonte: A própria pesquisa

\section{Cálculo das estimativas do VBP - Etapa 1}

Na Figura 2.1, a seta 1 indica o uso da pesquisa FAO/INCRA. A pesquisa disponibiliza informações desagregadas até o nível das unidades de produção, dentro de cada município. As principais atividades desenvolvidas pelas propriedades consideradas familiares ${ }^{2}$ podem ser avaliadas conforme o nível tecnológico da produção e como ela interage com os outros mercados. É possível identificar o grau de interdependências entre agronegócio familiar e o próprio setor agropecuário e, também, com os demais setores da indústria e comércio.

${ }^{2}$ Nesta pesquisa as propriedades consideradas familiares e patronais atendem aos mesmos critérios estabelecidos em INCRA (2000). 


\section{Cálculo das estimativas do VBP - Etapa 2}

A segunda etapa do esquema, indicado pela seta 2, refere-se ao meio escolhido para relacionar as informações do segmento familiar com as bases periódicas do IBGE. Através da caracterização espacial em nível microrregional $^{3}$, puderam ser definidos dois grupos de microrregiões, as predominantemente familiares a as predominantemente patronais. Por meio da pesquisa FAO/INCRA buscou-se classificar as microrregiões de acordo com dois aspectos principais: a participação do VBP familiar da microrregião no VBP familiar nacional e a importância do segmento familiar no VBP total de cada microrregião. Pela visualização do Gráfico 2.1, nota-se que $50 \%$ da produção nacional da agropecuária familiar está concentrada nas 81 microrregiões que detêm os maiores VBP familiar.

Gráfico 2.1 - Número de microrregiões e a participação acumulada no VBP familiar

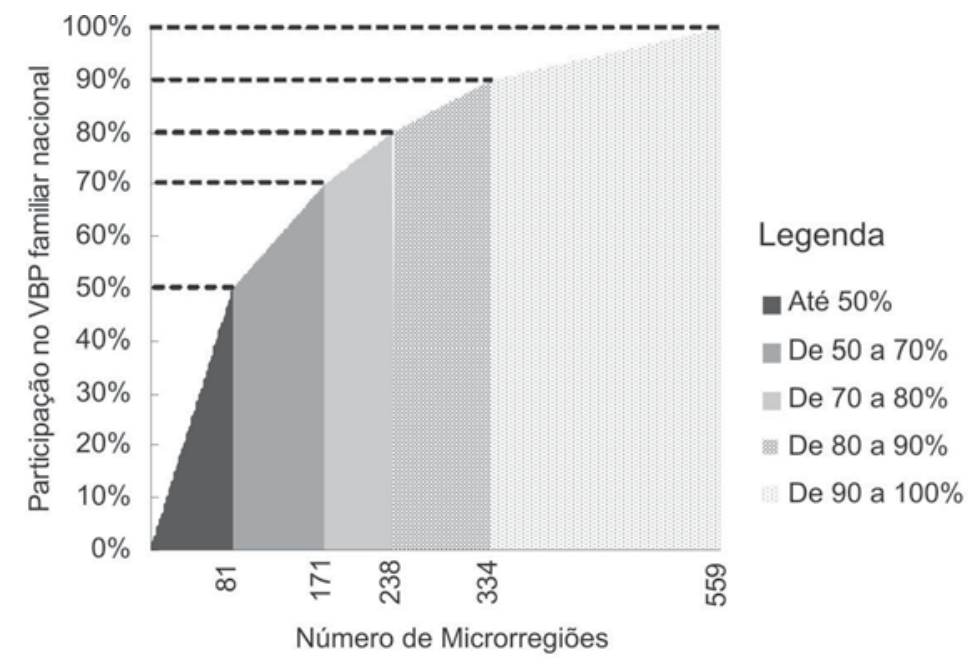

Fonte: Fao-Incra/Censo Agropecuário 95/96

O acúmulo marginal da participação no VBP nacional é decrescente à medida que as microrregiões restantes são adicionadas. Embora estas 81 microrregiões sejam importantes para o contexto agropecuário fami-

${ }^{3} \mathrm{O}$ agrupamento de municípios em microrregiões usado foi definido conforme o IBGE. 
liar, não é possível considerar que todas elas são predominantemente familiares. Conforme o Quadro 2.1 é possível observar que das $81 \mathrm{mi}-$ crorregiões, 31 não têm sistemas de produção regidos, em sua maioria, por propriedades consideradas familiares.

Quadro 2.1 - Importância das microrregiões segundo o volume da produção familiar e a participação familiar no VBP total da microrregião

\begin{tabular}{|c|c|c|c|c|c|c|}
\hline $\begin{array}{l}\begin{array}{r}\text { Participação do } \\
\text { segmento familiar } \\
\text { no VBP total da } \\
\text { microrregião }\end{array} \\
\text { Faixas de } \\
\text { acumulação do } \\
\text { VBP familiar } \\
\text { nacional }\end{array}$ & $\begin{array}{l}\text { Mais } \\
\text { de } \\
75 \%\end{array}$ & $\begin{array}{l}\text { Entre } \\
50 \% \text { e } \\
75 \%\end{array}$ & $\begin{array}{c}\text { Entre } \\
38 \% \text { e } \\
50 \%\end{array}$ & $\begin{array}{l}\text { Entre } \\
0 \% \text { e } \\
38 \%\end{array}$ & $\begin{array}{l}\text { Sub } \\
\text { total }\end{array}$ & $\begin{array}{l}\text { Participação } \\
\text { do VBP } \\
\text { familiar no } \\
\text { VBP total }\end{array}$ \\
\hline $\begin{array}{c}\text { Quantidade de } \\
\text { microrregiões que estão } \\
\text { na faixa de } 0 \text { a } 50 \%\end{array}$ & $\begin{array}{c}27 \\
(20 \%)\end{array}$ & $\begin{array}{c}23 \\
(17 \%)\end{array}$ & $\begin{array}{c}15 \\
(7 \%)\end{array}$ & $\begin{array}{c}16 \\
(6 \%)\end{array}$ & $\begin{array}{c}81 \\
(50 \%)\end{array}$ & $53 \%$ \\
\hline $\begin{array}{c}\text { Quantidade de } \\
\text { microrregiões que estão } \\
\text { na faixa de } 50 \text { a } 70 \%\end{array}$ & $\begin{array}{c}11 \\
(3 \%)\end{array}$ & $\begin{array}{c}20 \\
(5 \%)\end{array}$ & $\begin{array}{c}19 \\
(4 \%)\end{array}$ & $\begin{array}{c}40 \\
(9 \%)\end{array}$ & $\begin{array}{c}90 \\
(20 \%)\end{array}$ & $33 \%$ \\
\hline $\begin{array}{c}\text { Quantidade de } \\
\text { microrregiões que estão } \\
\text { na faixa de } 70 \text { a } 80 \%\end{array}$ & $\begin{array}{c}9 \\
(1 \%)\end{array}$ & $\begin{array}{c}18 \\
(3 \%)\end{array}$ & $\begin{array}{c}11 \\
(2 \%)\end{array}$ & $\begin{array}{c}29 \\
(4 \%)\end{array}$ & $\begin{array}{c}67 \\
(10 \%)\end{array}$ & $33 \%$ \\
\hline $\begin{array}{c}\text { Quantidade de } \\
\text { microrregiões que estão } \\
\text { na faixa de } 80 \text { a } 90 \%\end{array}$ & $\begin{array}{c}12 \\
(1 \%)\end{array}$ & $\begin{array}{c}29 \\
(3 \%)\end{array}$ & $\begin{array}{c}16 \\
(2 \%)\end{array}$ & $\begin{array}{c}39 \\
(4 \%)\end{array}$ & $\begin{array}{c}96 \\
(10 \%)\end{array}$ & $29 \%$ \\
\hline $\begin{array}{c}\text { Quantidade de } \\
\text { microrregiões que estão } \\
\text { na faixa de } 90 \text { a } 100 \%\end{array}$ & $\begin{array}{c}17 \\
(1 \%)\end{array}$ & $\begin{array}{c}58 \\
(3 \%)\end{array}$ & $\begin{array}{c}38 \\
(2 \%)\end{array}$ & $\begin{array}{c}112 \\
(4 \%)\end{array}$ & $\begin{array}{c}225 \\
(10 \%)\end{array}$ & $22 \%$ \\
\hline Sub total & $\begin{array}{c}76 \\
(26 \%)\end{array}$ & $\begin{array}{c}148 \\
(30 \%)\end{array}$ & $\begin{array}{c}99 \\
(16 \%)\end{array}$ & $\begin{array}{c}236 \\
(27 \%)\end{array}$ & $\begin{array}{c}559 \\
(100 \%)\end{array}$ & $38 \%$ \\
\hline $\begin{array}{l}\text { Participação do VBP } \\
\text { familiar no VBP total }\end{array}$ & $84 \%$ & $63 \%$ & $44 \%$ & $19 \%$ & $38 \%$ & \\
\hline
\end{tabular}

Fonte: Fao-Incra/Censo Agropecuário 95/96

No Quadro 2.1, a área destacada no canto superior esquerdo representa as microrregiões que podem ser consideradas prioritárias para a análise do desempenho no período posterior ao Censo. No outro extre- 
mo, situam-se as microrregiões que podem ser consideradas predominantemente patronais, pois as participações da agricultura familiar encontram-se abaixo da média nacional e, ao mesmo tempo, apresentam as menores contribuições ao VBP familiar nacional (151 microrregiões que geram somente $8 \%$ do VBP familiar, mas respondem por quase $1 / 3$ do VBP não familiar).

Resta, então, um grupo intermediário, onde estão aquelas predominantemente familiares, mas de pouca importância no VBP familiar nacional, até as caracteristicamente patronais, mas cuja participação no VBP familiar nacional é relativamente expressiva. Assim, por meio de outro critério de seleção, a classificação destas microrregiões intermediárias torna-se subordinada a outros aspectos, que levam em conta cada tipo de produto agropecuário que pode ser destacado na pesquisa FAO/INCRA. A saber: a) participação do segmento familiar no VBP do produto superior à média nacional; b) contribuição do VBP do produto no VBP total da microrregião superior ao observado nacionalmente; c) participação da região no VBP familiar do produto é superior a sua contribuição para o VBP familiar global.

Essa tipologia, embora trabalhosa, permitiu discriminar as regiões de maneira mais detalhada, considerando os principais produtos gerados pela agropecuária familiar. Cada microrregião foi analisada cuidadosamente uma a uma, a fim se caracterizar o comportamento da produção da agricultura familiar.

\section{Cálculo das estimativas do VBP - Etapa 3}

Após definidas as regiões familiares e patronais, os valores brutos de produção dos dois sistemas produtivos foram associados diretamente ao VBP das microrregiões correspondentes. O VBP total de uma microrregião familiar é contabilizado como VBP familiar, idem para o patronal.

Assim, o critério utilizado para estimar o VBP dos anos seguintes assume que a predominância da estrutura familiar foi mantida no período de 1997 a 2003, nas microrregiões consideradas familiares pela pesquisa FAO/INCRA de 1996. Considera-se, portanto, que a evolução dos sistemas de produção patronais, nos locais onde a predominância era familiar, não foi superior à evolução dos sistemas familiares. Da 
mesma forma, o inverso é verdadeiro, nas microrregiões cuja representatividade patronal era maior em 1996.

Obviamente, este critério pode estar sujeito à falhas. Para algumas regiões, estimativas e conclusões errôneas podem estar relacionadas com mudanças tecnológicas, legislativas, viárias ou devido à interferência das relações econômicas inter-regionais. Entretanto, acredita-se que na grande maioria das microrregiões, as peculiaridades locais que possibilitaram o êxito da produção familiar ou patronal não tenham sofrido grandes alterações nos últimos anos.

O desenvolvimento da agricultura familiar em muitos locais fez-se sob processos como aqueles inerentes à forma de colonização, a herança cultural dos povos colonizadores, a valorização da terra e a diferença de rentabilidade que existe entre os cultivos em pequena e larga escala, tendo em vista as especificidades de cada produto. Diante destas características é provável que regiões predominantemente familiares ainda o sejam, ao longo da última década. Infelizmente, esta justificativa só poderá ser ou não validada através da execução de outra pesquisa agropecuária censitária, como a de 1995/96, que possa abranger a totalidade do Brasil. Assim, neste trabalho optou-se pelo uso do critério mencionado, a fim de estimar o VBP familiar e, posteriormente, o Produto Interno Bruto relacionado com o complexo do agronegócio familiar.

\section{Cálculo das estimativas do VBP - Etapa 4}

Assumindo, então, que a dominância patronal ou familiar não é alterada nas microrregiões, avalia-se a variação do VPB de cada produto considerado 4 ao longo do tempo, através das pesquisas periódicas do IBGE: Pesquisa Agrícola Municipal (PAM), Pesquisa Pecuária Municipal (PPM), Pesquisa Trimestral do Leite, Pesquisa Trimestral de Abate e da Pesquisa da Extração Vegetal e Silvicultura (IBGE, 1997-2004).

Com os dados anuais de cada levantamento determinaram-se as variações da produção dos produtos agropecuários. Este percentual é vinculado à participação de cada produto dentro do VBP em cada mi-

${ }^{4}$ Os produtos considerados neste trabalho correspondem àqueles avaliados na pesquisa do FAO/INCRA. A saber, são: 22 cultivos agrícolas, 4 produções animais e 3 conjuntos de atividades (extrativismo vegetal, silvicultura e produção de hortaliças), universo de atividades que responde por $94,3 \%$ e $92,5 \%$ do VBP nacional total e familiar, respectivamente. 
crorregião. Para alguns produtos (leite, por exemplo), a indisponibilidade de dados municipais, pelas pesquisas periódicas do IBGE, impossibilita a especificação microrregional por isso a participação no VBP foi relacionada em nível estadual.

\section{Cálculo das estimativas do VBP - Etapa 5}

A pesquisa FAO/INCRA foi usada para distinguir as microrregiões familiares das patronais e avaliar a importância de cada produto dentro de cada contexto, enquanto que as pesquisas agropecuárias periódicas do IBGE forneceram as variações regionais anuais da produção de cada produto. A ligação entre as pesquisas foi dada, para a maioria dos produtos no âmbito microrregional e, em alguns casos, estadual. Isto resultou em estimativas anuais do VBP nacional familiar e patronal por categorias de produtos agropecuários.

\subsection{Estimativa do PIB do agronegócio familiar}

A própria tabulação das estimativas do VBP proporciona a obtenção de resultados que permitem entender a influência familiar sobre a economia agropecuária nacional. Entretanto, apenas com o uso de uma análise descritiva, não é possível avaliar a importância da agropecuária familiar em relação ao Produto Interno Bruto nacional. Ressalta-se que este trabalho visa dimensionar, não apenas a contribuição dada pelo setor produtivo da agropecuária familiar, mas sim de todo complexo econômico vinculado a esse setor. Isto inclui o cômputo que reúne, além da produção do setor familiar, a demanda por insumos, a indústria de transformação da produção em bens manufaturados e o quanto é gerado nas etapas de comercialização e distribuição de produtos e insumos, relacionados, sempre, com os estabelecimentos familiares. Neste trabalho, todo este conjunto de atividades é denominado agronegócio familiar.

Diferencia-se, portanto, a importância do setor da agropecuária familiar do contexto maior que está associado à magnitude do agronegócio familiar. Para dimensionar quantitativamente tal aspecto, optou-se por estimar o valor da produção de bens e serviços do agronegócio familiar, ocorrido dentro do país, ou seja, optou-se pelo cálculo do PIB do agronegócio familiar. 
Através dos modelos de insumo produto é possível mensurar o PIB total de uma economia ou de suas partes. Os fundamentos destes modelos e a própria teoria, inicialmente proposta por Leontief (1986) e aperfeiçoada com o decorrer dos anos por outros autores, são adequados para atingir os objetivos deste trabalho.

As matrizes insumo produto são elementos essenciais para o desenvolvimento dos modelos derivados da teoria de Leontief: elas traduzem o encadeamento lógico e quantitativo existente entre os setores produtivos. Embora estes setores sejam agregados em grandes grupamentos, através dos dados da pesquisa FAO/INCRA é possível desagregar o setor agropecuário, existente nas matrizes estimadas para o Brasil, de forma a enfatizar a dicotomia entre o agronegócio familiar e o patronal.

Para o âmbito nacional brasileiro, a matriz insumo produto mais recente publicada pelo IBGE data do ano de 1996 (IBGE, 1996), por isso, para fins deste trabalho foram estimadas as matrizes para os anos faltantes compreendidos entre 1995 a 2003, de acordo com os métodos desenvolvidos por Guilhoto e Sesso Filho (2005). As matrizes estimadas derivam do Sistema de Contas Nacionais (IBGE, 1996-2002) e o modelo de insumo produto utilizado para estimar o valor do agronegócio é descrito no item subseqüente.

\subsubsection{Estimação do PIB do agronegócio familiar pelo Modelo de Insumo-Produto}

A metodologia para o cálculo do PIB do agronegócio familiar e patronal baseia-se na mesma técnica empregada no cálculo do agronegócio em geral, conforme Furtuoso e Guilhoto (2003), o modelo fundamentase na intensidade da interligação para trás e para frente da agropecuária propriamente dita.

Analogamente à estimativa do PIB do agronegócio total, o PIB do agronegócio familiar resulta da soma de quatro agregados principais: insumos, agropecuária, indústria e distribuição. O método envolve a idéia de se considerar, além da agropecuária propriamente dita, as atividades que alimentam e são alimentadas pela produção rural, considerando a interdependência existente entre as atividades de produção.

O método referenciado nas expressões a seguir pode ser observado 
de uma forma esquemática nas Figuras 2.1 e 2.2, que apresentam o processo de obtenção do PIB do Agronegócio.

Figura 2.1 - Esquematização do processo de obtenção do PIB do agronegócio familiar - soma dos agregados

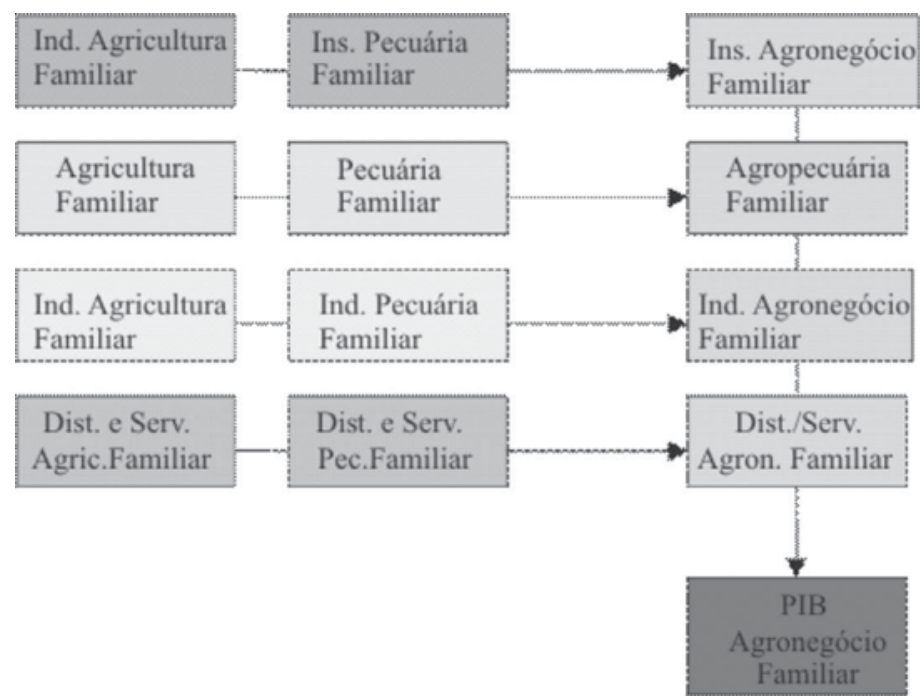

Fonte: Adaptado de Furtuoso e Guilhoto (2003)

Figura 2.2 - Esquematização do processo de obtenção do PIB do agronegócio familiar - soma dos complexos agrícola e pecuário

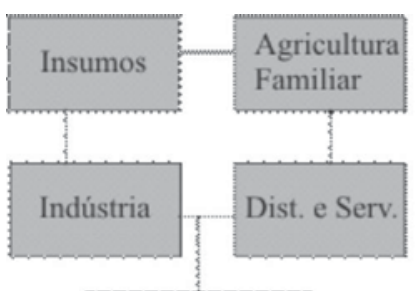

PIB Agricultura Familiar

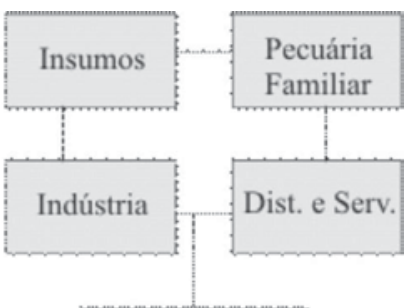

PIB Pecuária Familiar

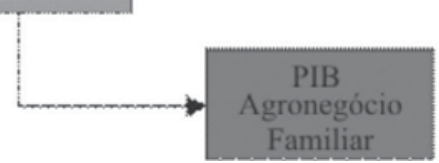

Fonte: Adaptado de Furtuoso e Guilhoto (2003) 
Observa-se que o PIB do Agronegócio pode ser obtido tanto pela soma ponderada do PIB dos agregados como pela soma ponderada dos PIBs da Agricultura e da Pecuária.

No cálculo do PIB do Agregado I (Insumos para a Agricultura e Pecuária Familiares) são utilizadas as informações referentes aos valores dos insumos adquiridos pela Agricultura e Pecuária e que estão disponíveis nas tabelas de insumo-produto.

Antes de se calcular o valor do PIB do Agregado I é necessário determinar os coeficientes de valor adicionado por setor. Depois de obtidos os coeficientes, calcula-se o PIB do Agregado I para os complexos da agricultura familiar e pecuária familiar.

$V A_{i}^{P M}=V A_{i}^{P B}+I I L_{i}-D u F_{i}$

$C V A_{i}=\frac{V A_{i}^{P M}}{X_{i}}$

Sendo:

$X_{i}=$ produção do setor $i$

$V A_{i}^{P M}=$ valor adicionado a preços de mercado do setor $i$

$V A_{i}^{P B}=$ valor adicionado a preços básicos do setor $i$

$I I L_{i}=$ impostos indiretos líquidos do setor $i$

$D u F_{i}=$ dummy financeira do setor $i$

$P I B_{k}^{I}=\sum_{i=1}^{n} z_{i k} \cdot C V A_{i}$

Sendo:

$i=1,2, \ldots, 43$ setores restantes

$z_{i k}=$ valor total do insumo do setor $i$ para a agricultura familiar ou pecuária familiar

$P I B_{k}^{I}=$ PIB do agregado I para agricultura familiar $(k=1)$ e pecuária familiar $(k=2)$

$C V A_{i}=$ coeficiente de valor adicionado do setor $i$

Para o Agregado II (propriamente, o Setor da Agricultura e Pecuária Familiares) consideram-se no cálculo os valores adicionados gerados pelos respectivos setores e subtraem-se dos valores adicionados destes setores os valores que foram utilizados como insumos. 
$P I B_{k}^{I I}=V A_{k}^{P M}-\sum_{i=1}^{n} z_{i k} \cdot C V A_{i}$

Sendo:

$P I B_{k}^{I I}=$ PIB do agregado II para agricultura familiar $(k=1)$ e pecuária familiar $(k=2)$

e as outras variáveis são como definidas anteriormente

Para definir a composição do Agregado III, as Indústrias de Base Agrícola, foram adotados vários indicadores, como por exemplo: a) os principais setores demandantes de produtos agrícolas, obtidos através da estimação da matriz de insumo-produto; b) as participações dos insumos agrícolas no consumo intermediário dos setores agroindustriais; e c) as atividades econômicas que efetuam a primeira, segunda e terceira transformações das matérias-primas agrícolas. A estimação do Agregado III adota o somatório dos valores adicionados pelos setores agroindustriais subtraídos dos valores adicionados destes setores que foram utilizados como insumos do Agregado II.

$P I B_{k}^{I I I}=\sum_{q=1}^{m}\left(V A_{q}^{P M}-z_{q k} \cdot C V A_{q}\right)$

Sendo:

$q=$ corresponde aos $m$ setores que compõem o conjunto de indústrias de base agrícola $P I B_{k}^{I I I}=$ PIB do agregado III para agricultura familiar $(k=1)$ e pecuária familiar $(k=2)$ e as outras variáveis são como definidas anteriormente

No caso do Agregado IV, referente à Distribuição Final, considera-se para fins de cálculo o valor agregado dos setores relativos ao Transporte, Comércio e segmentos de Serviços. Do valor total obtido, destina-se ao Agronegócio Familiar apenas a parcela que corresponde à participação dos produtos agropecuários e agroindustriais na demanda final de produtos. A sistemática adotada no cálculo do valor da distribuição final do agronegócio industrial pode ser representada por: 


$$
\begin{aligned}
& D F D=D F G-I I L_{D F}-P I_{D F} \\
& M C=V A T_{P M}+V A C_{P M}+V A S_{P M} \\
& P I B_{k}^{I V}=M C . \frac{D F_{k}+\sum_{q=1}^{m} D F_{q}}{D F D}
\end{aligned}
$$

Sendo:

$D F G=$ demanda final global

$I I L_{D F}=$ impostos indiretos líquidos pagos pela demanda final

$P I_{D F}=$ produtos importados pela demanda final

$D F D=$ demanda final doméstica

$V A T_{P M}=$ valor adicionado do setor transporte a preços de mercado

$V A C_{P M}=$ valor adicionado do setor comércio a preços de mercado

$V A S_{P M}=$ valor adicionado do setor serviços a preços de mercado

$M C=$ margem de comercialização

$D F_{k}=$ demanda final da agricultura $(k=1)$ e pecuária $(k=2)$ familiares

$D F_{q}=$ demanda final dos setores agroindustriais

$P I B_{k}^{I V}=$ PIB do agregado IV para agricultura familiar $(k=1)$ e pecuária familiar $(k=2)$

e as outras variáveis são como definidas anteriormente

O PIB total dos dois complexos que compõem o agronegócio familiar é dado pela soma dos seus agregados, ou seja:

$P I B_{k}^{\text {AgrFamiliar }}=P I B_{k}^{I}+P I B_{k}^{I I}+P I B_{k}^{I I I}+P I B_{k}^{I V}$

Sendo:

$k=1,2$

E o PIB agronegócio familiar total é dado por:

$P I B^{\text {AgrFamiliar }}=P I B_{1}^{\text {AgrFamiliar }}+P I B_{2}^{\text {AgrFamiliar }}$

Destaca-se que o problema de dupla contagem, comumente apresentado em estimativas do PIB do Agronegócio, quando se levam em consideração os valores dos insumos e não o valor adicionado efetivamente gerado na produção destes, foi eliminado. Os cálculos dos quatro agregados que compõem o PIB do agronegócio familiar respeitam este aspecto dentro de suas equações.

O método apresentado para estimar o PIB do agronegócio familiar foi empregado para todos os anos de 1996 a 2003 e os resultados são apresentados no item seguinte. 


\section{Resultados e discussão}

Conforme as bases teóricas empregadas neste trabalho, o agronegócio foi definido e mensurado para dois grandes complexos: agricultura e pecuária, sendo que cada complexo pode ser dividido em quatro componentes principais: a) insumos; b) o próprio setor; c) processamento; e d) distribuição e serviços.

Além da possibilidade de se avaliar cada um dos quatro componentes dentro de cada um dos dois complexos, outra subdivisão relacionada com o objetivo principal da pesquisa - a distinção entre o Agronegócio Familiar ou Patronal - torna possível multiplicar ainda mais as formas de desagregação das análises. A Figura 4.1 apresenta a seqüência lógica de desagregação da interpretação analítica dos resultados.

Figura 4.1 - Fluxo do processo de análise de acordo com a seqüência metodológica

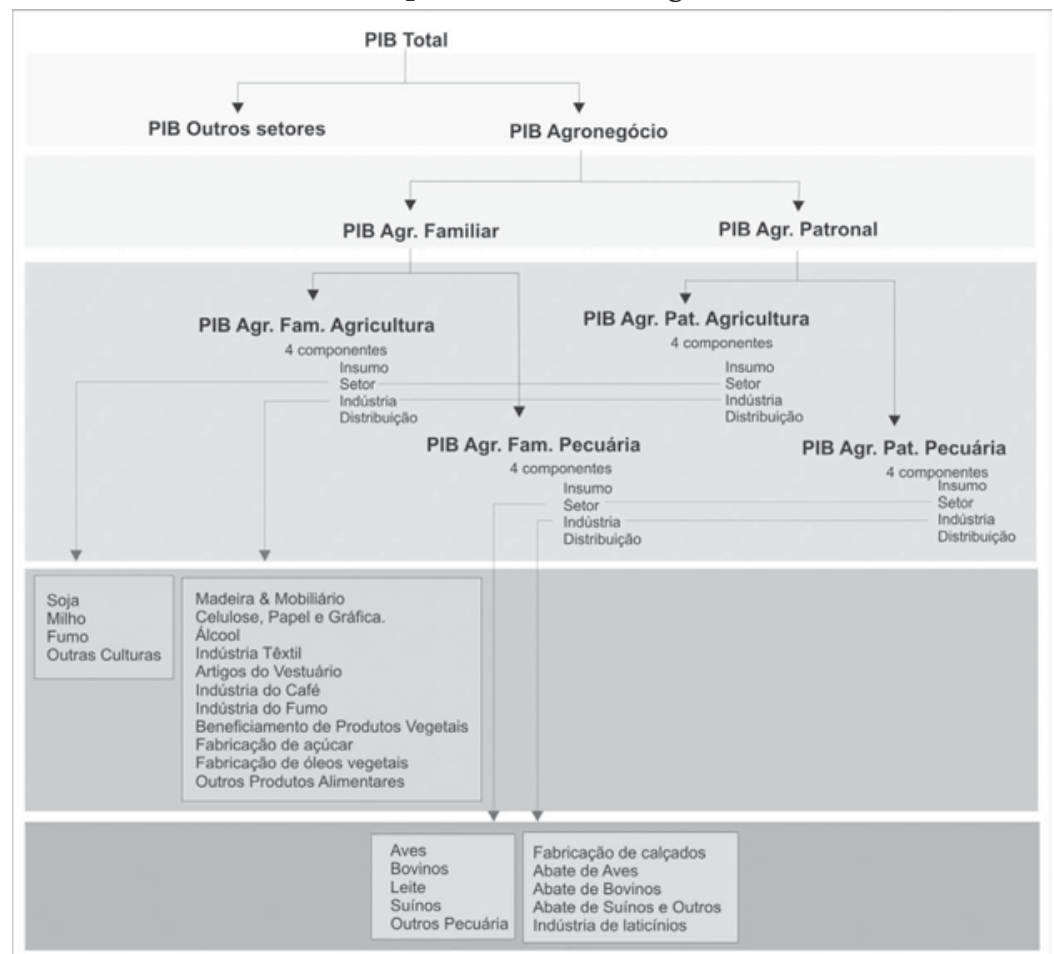

Fonte: A própria pesquisa 


\subsection{Desempenho do PIB do agronegócio do Brasil}

No período de análise (1995 a 2003) o PIB do Brasil teve um crescimento acumulado de quase $16 \%$, chegando a $\mathrm{R} \$ 1.556$ milhões de reais em 2003. Por sua vez, o agronegócio, apesar de apresentar taxas de crescimento anuais baixas, ou mesmo negativas até 2001, tem uma acentuada ascensão em 2002 e 2003 por conta do contexto internacional e nacional que favoreceu seu crescimento (Gráfico 3.1). No período, o aumento em valores reais do PIB agronegócio acumulou quase 18\%, elevando sua participação, com relação ao PIB total do Brasil, de 30,1\% em 1995 para 30,6\% em 2003, conforme demonstrado no Gráfico 3.1.

Gráfico 3.1 - Evolução acumulada do PIB do agronegócio e sua participação no PIB total da economia brasileira

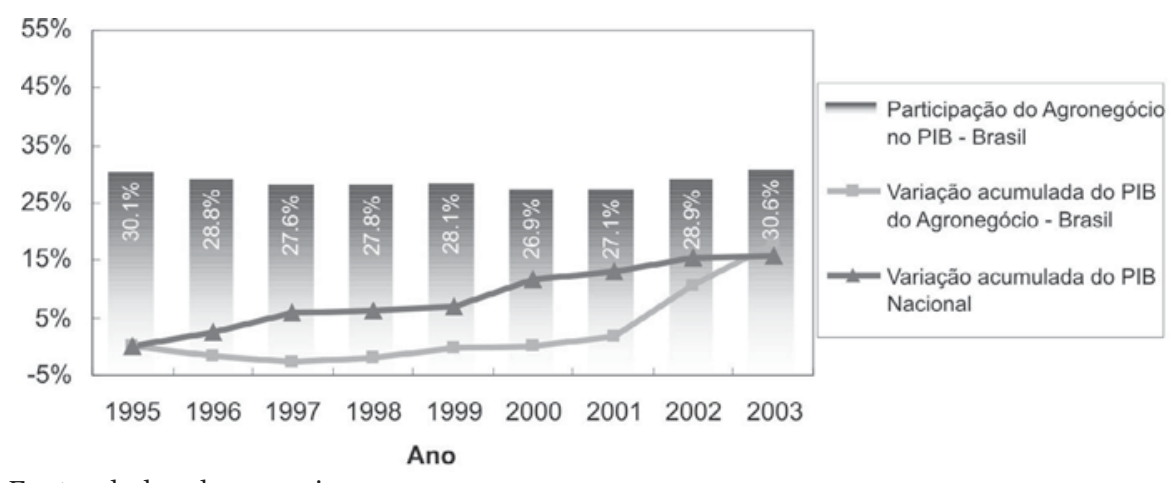

Fonte: dados da pesquisa

Entre 1995 a 1997 as taxas de crescimento foram negativas tanto para o complexo do agronegócio pecuário como o do agrícola. A partir de 1997, a produção pecuária admitiu uma tendência positiva, mas o agronegócio associado às lavouras continuou em declínio até 2001. Embora a participação do complexo agrícola no todo do agronegócio brasileiro seja maior que a do complexo pecuário (respectivamente, $69,7 \%$ e $30,3 \%$, em 2003), o agronegócio obteve um tímido crescimento nos anos de 1997 a 2001, por conta da pecuária. Após 2001, a produção da agricultura cresceu vertiginosamente, junto a um crescimento mais moderado da pecuária, resultando na forte ascensão do agronegócio total de forma a superar os outros setores da economia, como é demonstrado no Gráfico 3.1, nos anos de 2001 a 2003. 


\subsection{O Desempenho do agronegócio familiar e patronal do Brasil}

O segmento familiar da agropecuária brasileira e as cadeias produtivas a ela interligadas responderam, em 2003 , por $10,1 \%$ do PIB brasileiro (Gráfico 3.2). Tendo em vista que o conjunto do agronegócio nacional foi responsável, nesse mesmo ano, por 30,6\% do PIB, fica evidente o peso da agricultura familiar na geração de riqueza do país. Ao longo do período analisado, aproximadamente, um terço do agronegócio brasileiro está condicionado a produção agropecuária familiar.

Gráfico 3.2 - Participação do PIB do agronegócio familiar e patronal no PIB do Brasil

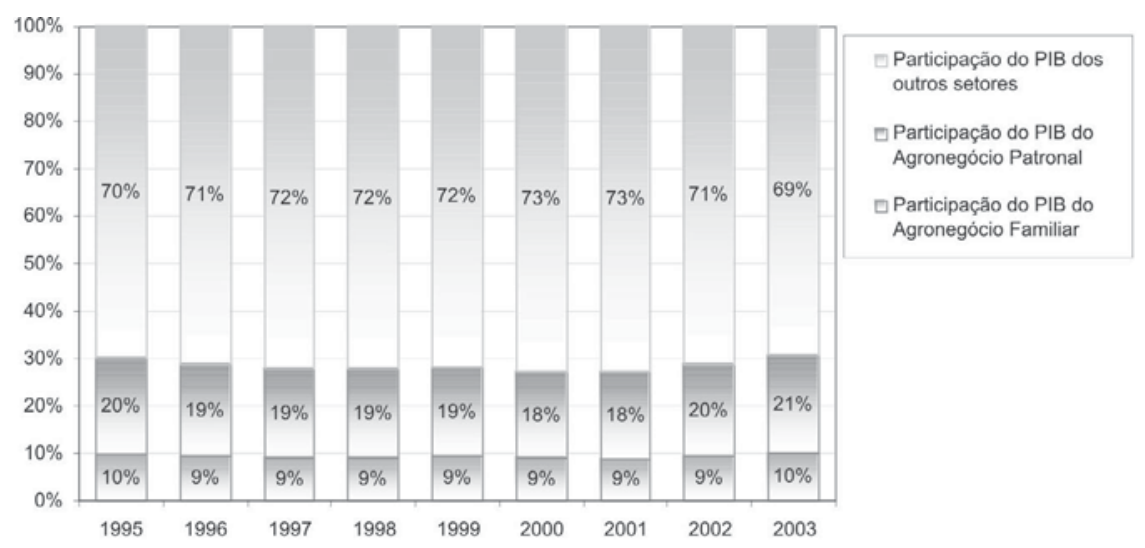

Fonte: dados da pesquisa

No período de 1995 a 2003, quando o agronegócio brasileiro é dividido nos quatro complexos que o compõem - patronal pecuário, patronal agrícola, familiar pecuário e familiar agrícola -, observa-se que apesar das oscilações, as proporções das participações não sofrem modificações muito drásticas (Gráfico 3.3).

Os complexos agrícolas são aqueles que têm maior expressão, sendo que a produção patronal agrícola é a mais importante na composição do agronegócio brasileiro. No período, o único setor a aumentar a sua participação foi o segmento familiar pecuário, elevando a sua participação de 11,0\% em 1995 para 12,3\% em 2003. Isto se deve, basicamente, ao acentuado aumento da produção animal advindo dos 
sistemas produtivos familiares entre os anos de 1997 a 2000, conforme o Gráfico 3.4.

Gráfico 3.3 - Participações dos complexos agropecuários familiar e patronal no PIB do agronegócio brasileiro

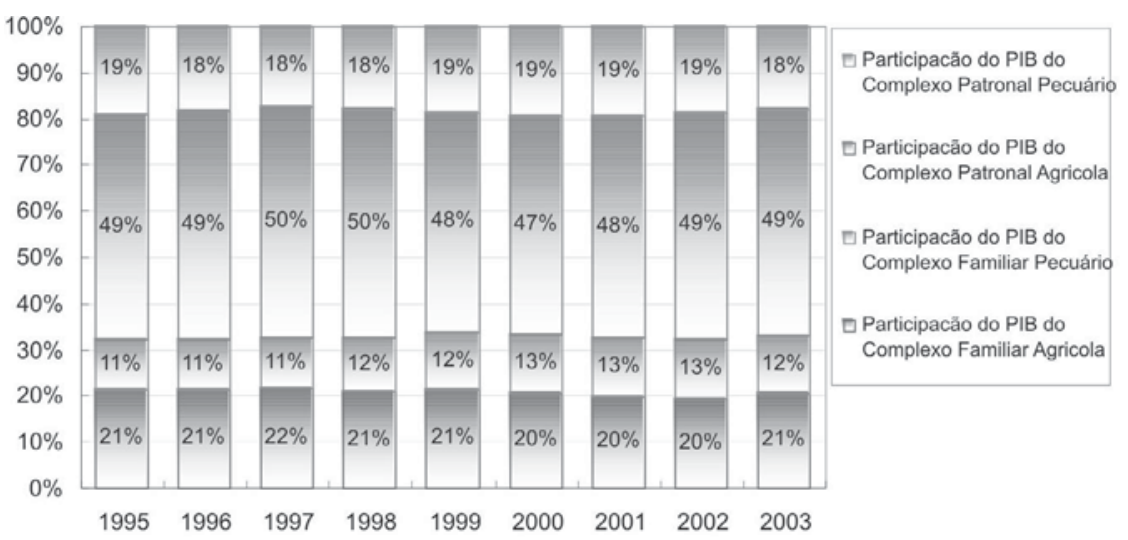

Fonte: dados da pesquisa

Gráfico 3.4 - Variaç̃es anuais acumuladas do PIB do agronegócio referentes aos complexos agropecuários familiar e patronal (ano base 1995)

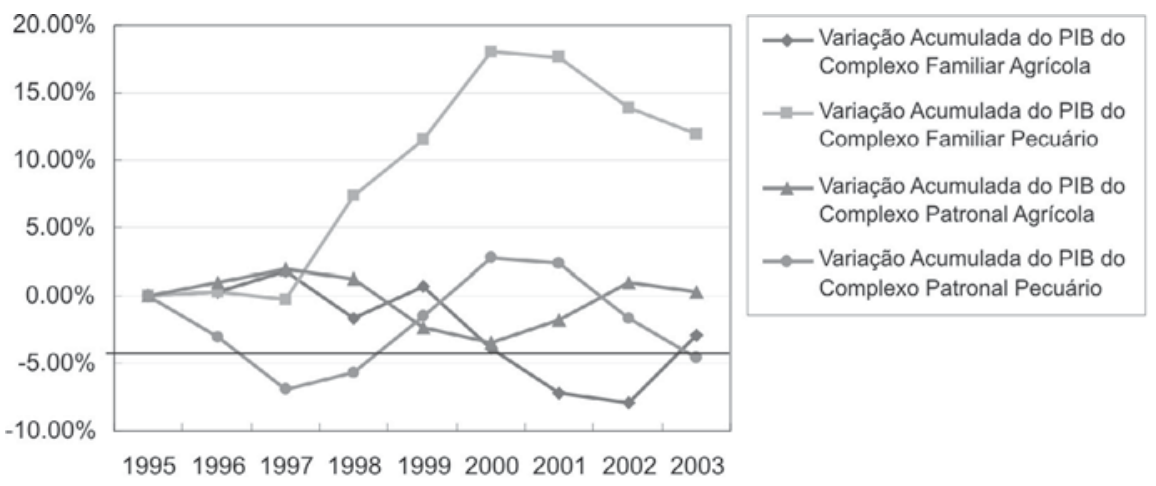

Fonte: dados da pesquisa 


\subsection{Os componentes do complexo agrícola familiar e patronal do Brasil}

No Brasil, as quantias percentuais relacionadas com cada um dos quatro componentes do agronegócio familiar agrícola são diferentes àquelas referentes ao agronegócio patronal. Além disso, no decorrer dos anos, percebem-se mudanças na composição do agronegócio da agricultura familiar e patronal. O Gráfico 3.5 ilustra este fato. Em geral, para os segmentos familiar e patronal observa-se um aumento da participação dos insumos e do setor agricultura, uma queda na participação da indústria de transformação, e um aumento na participação do setor de distribuição no caso da agricultura familiar e uma queda na patronal.

Gráfico 3.5 - Participação dos quatro componentes que formam o agronegócio agrícola familiar e patronal do Brasil

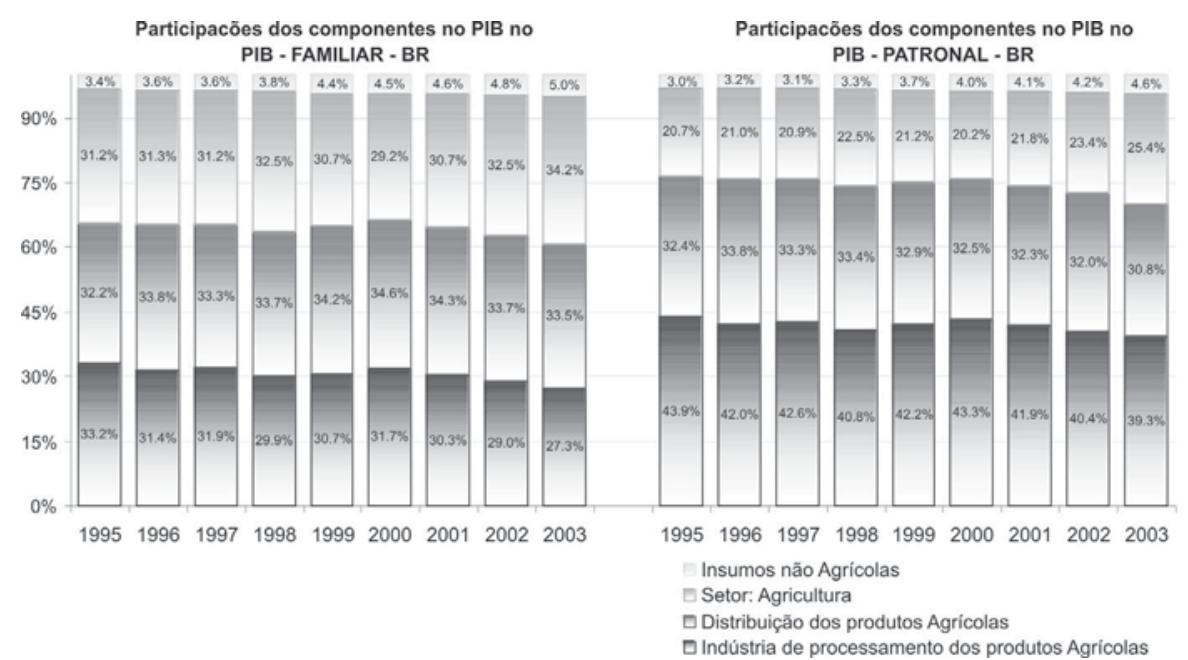

Fonte: dados da pesquisa

Na sua composição, a indústria tem um peso muito maior no agronegócio da agricultura patronal (39,3\% em 2003) do que no agronegócio da agricultura familiar (27,3\% em 2003), sendo este fato uma indicação que boa parte da produção familiar não passa por um processo de transformação, reduzindo desta forma a possibilidade de agregação de valor dentro da cadeia produtiva do universo familiar. 


\subsection{Os componentes do complexo pecuário familiar e patronal do Brasil}

Diferente do complexo agrícola, as quantias percentuais, relacionadas com a participação de cada um dos componentes do agronegócio familiar pecuário, são bem próximas daquelas referentes ao agronegócio patronal como pode ser observado no Gráfico 3.6. Verifica-se também que o comportamento das séries ao longo do período também é semelhante. O setor de distribuição deteve a maior participação no complexo pecuário com aproximadamente $38 \%$ e $40 \%$ do agronegócio da pecuária familiar e patronal, respectivamente. O inverso ocorre com o setor de insumos, com participação próxima aos $10 \%$ para o patronal e familiar. Entretanto, o PIB do setor de insumos pecuários teve o maior crescimento, para o caso familiar o aumento é da ordem de $109 \%$, aumentando a participação deste componente de 6\% em 1995 para 9,6\% em 2003. O mesmo foi observado para o setor de insumos da pecuária patronal, mas em menor escala. Em contrapartida o setor industrial não teve o mesmo desempenho, perdendo importância no contexto geral. Sendo que o PIB da indústria relacionada com pecuária patronal apresentou variação negativa acumulada em $12 \%$.

Gráfico 3.6 - Participação dos 4 componentes que formam o agronegócio da pecuária familiar e patronal do Brasil

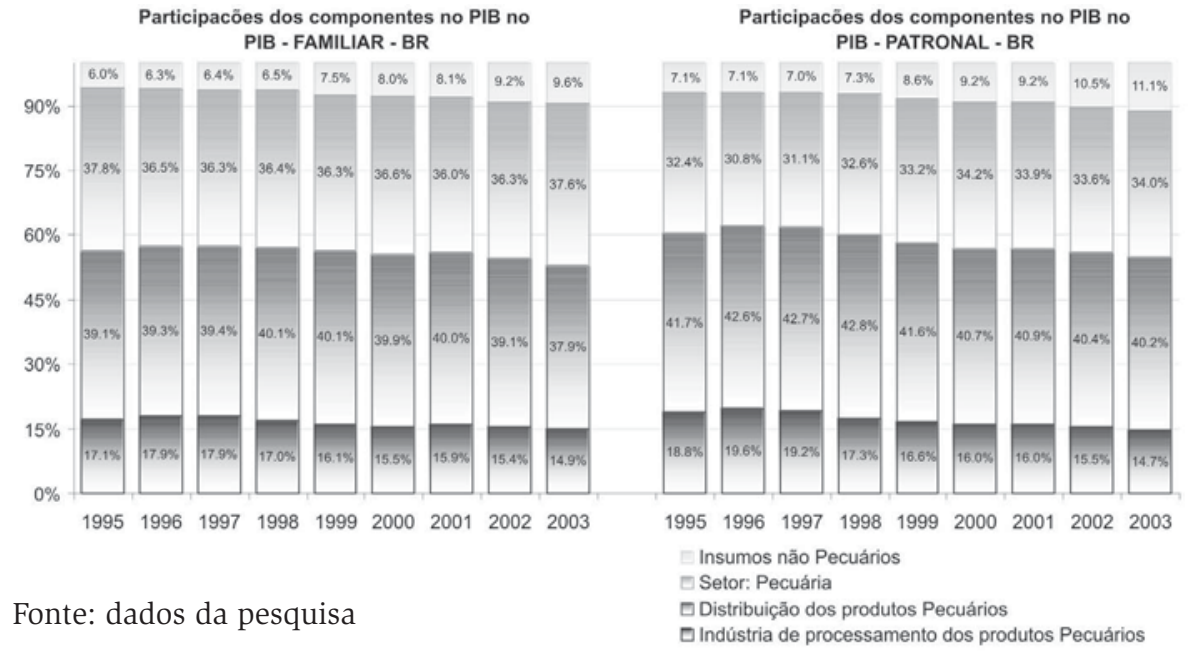




\subsection{A análise dos componentes agrícolas: setor e a indústria}

O Gráfico 3.7 detalha o PIB do componente: setor agrícola, relacionado com a agricultura familiar. As barras demonstram a participação das culturas de soja, milho, fumo e das restantes, ao longo dos anos. As linhas expõem as variações acumuladas do PIB das culturas de soja, milho, fumo e das demais. Nesses gráficos a interpretação das variações deve ser realizada pelo eixo da direita.

As mesmas análises, quando geradas para o contexto patronal, não resultam em números radicalmente diferentes daqueles apresentados no Gráfico 3.7. As participações das culturas de milho e soja foram de 2 a $3 \%$ maiores no sistema produtivo patronal, em todos os anos. A maior diferença estrutural observada consiste na presença marcante de cerca de $4 \%$ da cultura do fumo nas propriedades familiares, fato praticamente inexistente no ambiente patronal. Isto se deve a forte influência da fumicultura do Rio Grande do Sul, atividade ligada às pequenas propriedades, consideradas familiares no estado gaúcho.

Gráfico 3.7 - Participação de algumas culturas que formam o setor da agricultura Familiar no Brasil e as respectivas variações acumuladas do PIB

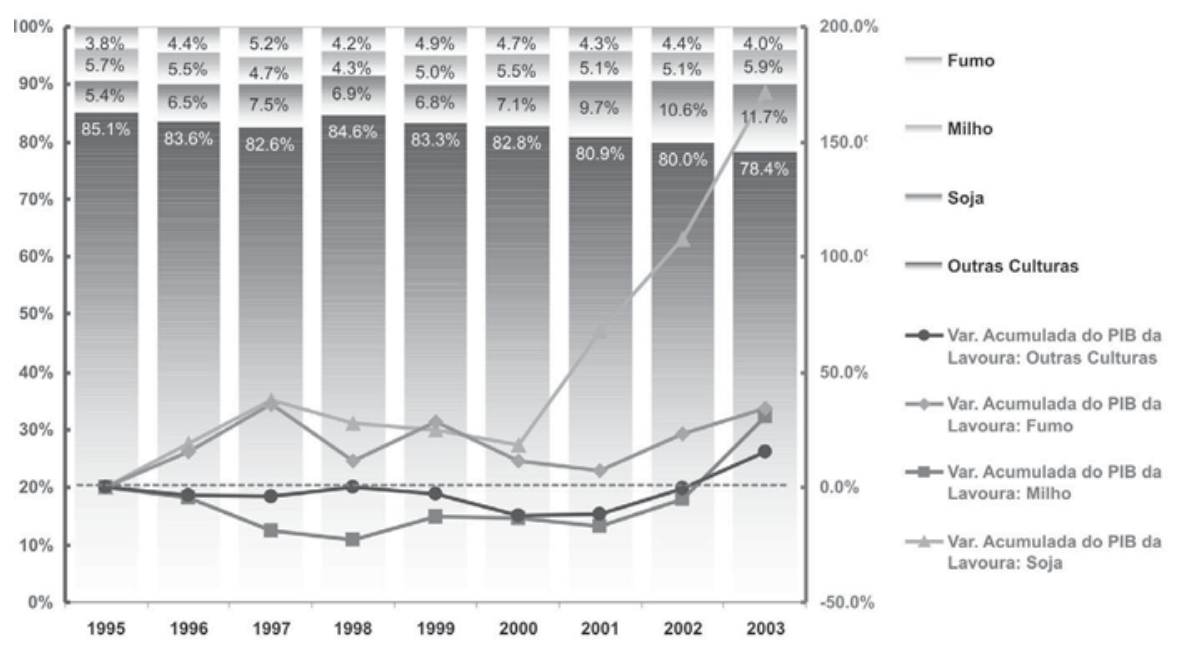

Fonte: dados da pesquisa 
Ainda pelo Gráfico 3.7, a cultura da soja é a que apresenta o maior crescimento no período de análise. O acréscimo do PIB da sojicultura corresponde a uma variação de $172 \%$, quase toda efetivada após o ano de 2000. Destaca-se também que após 2001 todas as culturas tiveram desempenho favorável. Estas considerações também servem para o sistema patronal, exceto para o fumo. Menciona-se apenas que o PIB da cultura da soja deteve um crescimento acumulado ainda maior, aproximadamente $230 \%$.

As mudanças ocorridas na indústria de processamento da produção agrícola familiar, decorrentes no ano de 1995 a 2003, podem ser avaliadas pelo Gráfico 3.8.

Gráfico 3.8 - Participação das indústrias vinculadas à agricultura familiar do Brasil

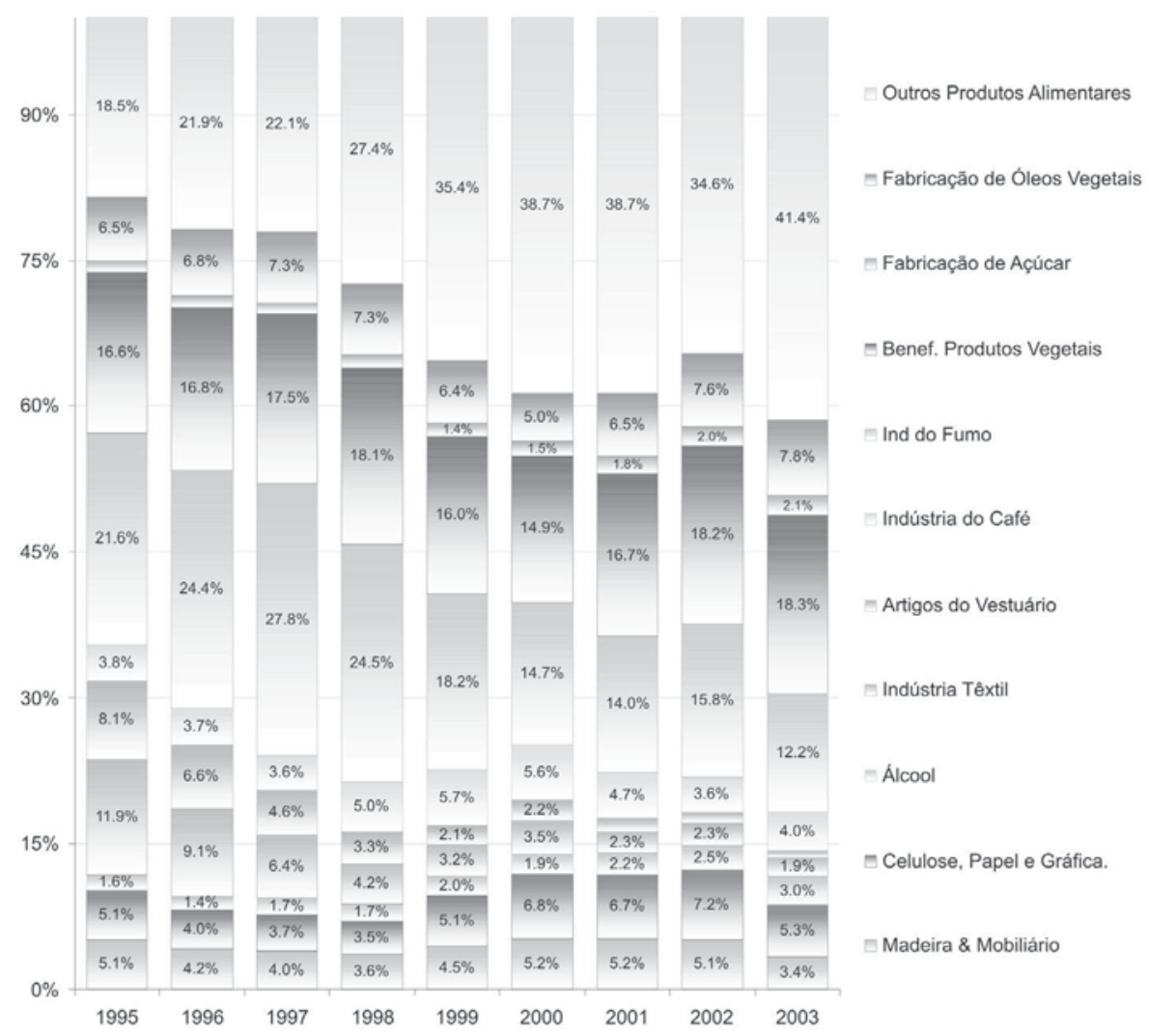

Fonte: dados da pesquisa 
Nos setores industriais ligados à produção vegetal, sobressaem-se, no segmento patronal, as ligadas ao reflorestamento, à cana-de-açúcar, e à soja. Por outro lado, no agronegócio ligado aos agricultores familiares o grande grupo dos outros produtos alimentares abrangeu, em 2003, mais de $40 \%$ de todo o PIB da Indústria das Lavouras do segmento familiar, tendo uma evolução significativa após 1995. Isso pode indicar uma maior diversificação produtiva dos agricultores familiares. Há, contudo, que sublinhar a importância das indústrias do fumo e, em menor grau, de fabricação de óleos vegetais e de beneficiamento de produtos vegetais, no caso do segmento familiar.

\subsection{A análise dos componentes pecuários: setor e a indústria}

Os Gráficos 3.9 e 3.10 apresentam a participação do PIB das criações no Setor Pecuário, relativas ao Agronegócio Familiar e Patronal. Pelos dois gráficos observa-se que as parcelas percentuais determinadas para cada tipo de criação são diferentes.

Gráfico 3.9 - Participação das criações que formam o setor da pecuária familiar no Brasil e as respectivas variações acumuladas do PIB

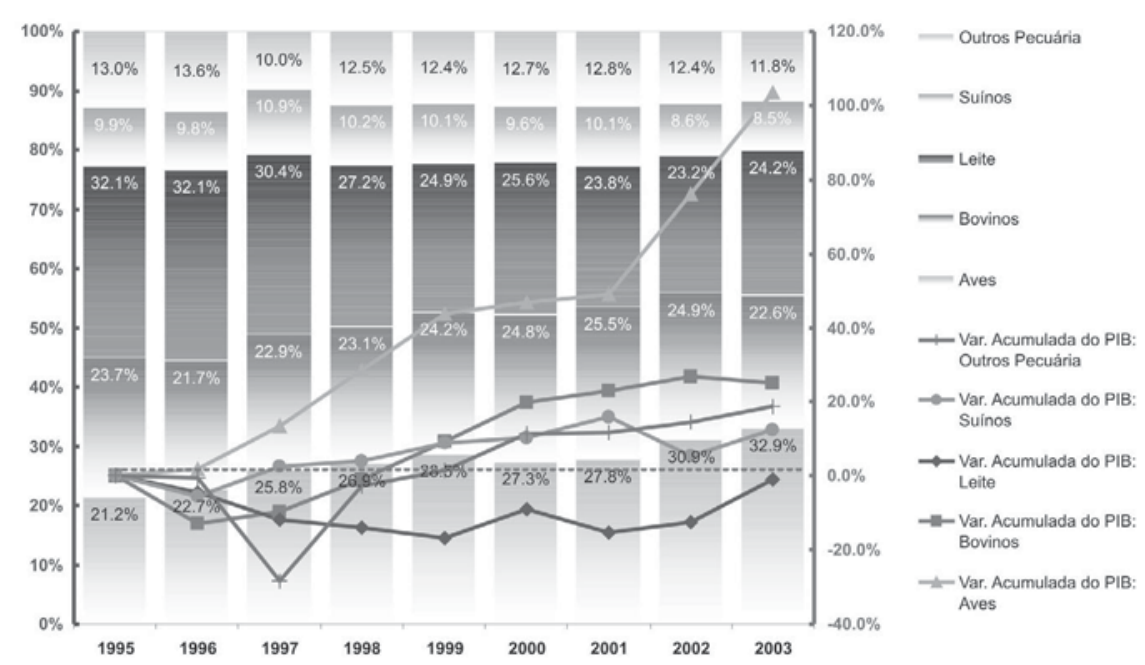

Fonte: dados da pesquisa

Pelo Gráfico 3.9, a criação de aves é responsável, em 2003, pela maior parcela do PIB do agronegócio pecuário familiar (33\%), sendo 
que em 1995 a maior importância era atribuída ao setor leiteiro (31\%). No agronegócio patronal, Gráfico 3.10, a bovinocultura de corte era o setor predominante em 1995 e ficou ainda mais com o decorrer dos anos (47\%, em 2003). Junto a ela a avicultura também ganhou espaço, em detrimento da bovinocultura de leite.

Gráfico 3.10 - Participação das criações que formam o setor da pecuária patronal no Brasil e as respectivas variações acumuladas do PIB

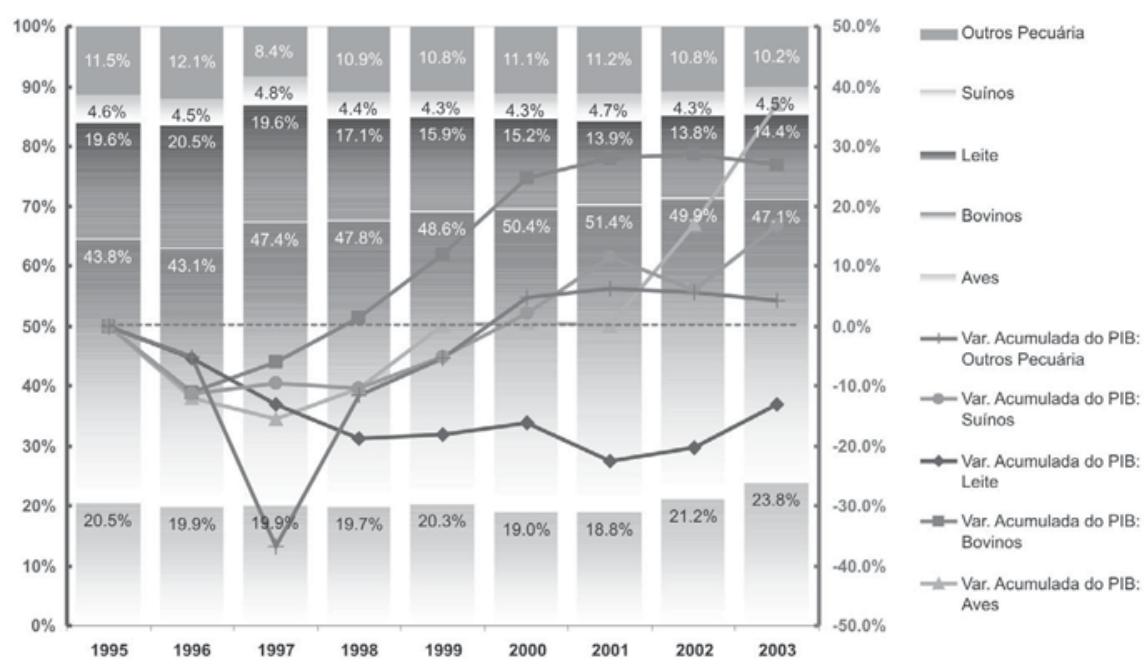

Fonte: dados da pesquisa

Comparando os dois gráficos nota-se que a importância do setor leiteiro, de aves e suínos é bem menor quando comparada a do universo familiar. A maior variação acumulada do PIB do setor pecuário tanto para o agronegócio familiar como patronal corresponde ao desenvolvimento da produção de aves.

Na indústria pecuária, representada pelos gráficos 3.11 e 3.12, O segmento patronal é dominado basicamente pelas atividades industriais ligadas à bovinocultura de corte, ou seja, o abate de bovinos e a fabricação de calçados. O abate de aves, a indústria de lacticínios, o abate de suínos são os ramos industriais que exibem uma participação expressiva na composição da indústria pecuária ligada ao segmento familiar e que, ademais, se reflete em um predomínio desse segmento no conjunto dessas indústrias. 
Gráfico 3.11 - Participação das indústrias que formam o setor da pecuária familiar no Brasil e as respectivas variações acumuladas do PIB

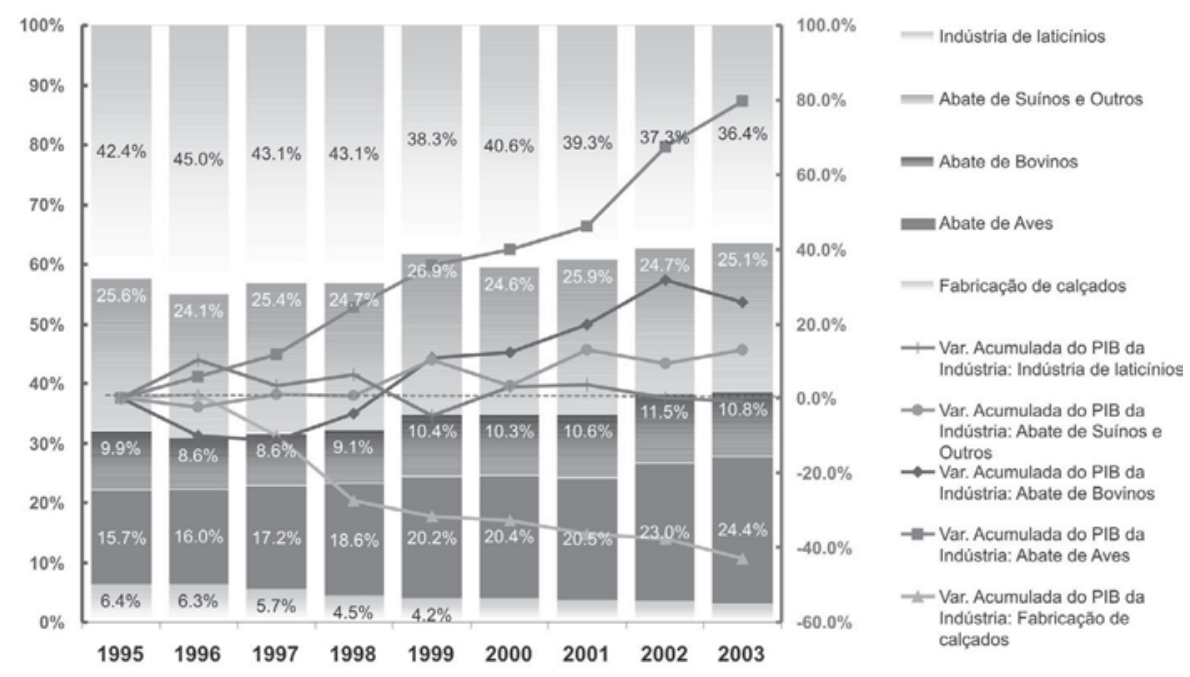

Fonte: dados da pesquisa

Gráfico 3.12 - Participação das indústrias que formam o setor da Pecuária Patronal no Brasil e as respectivas variações acumuladas do PIB

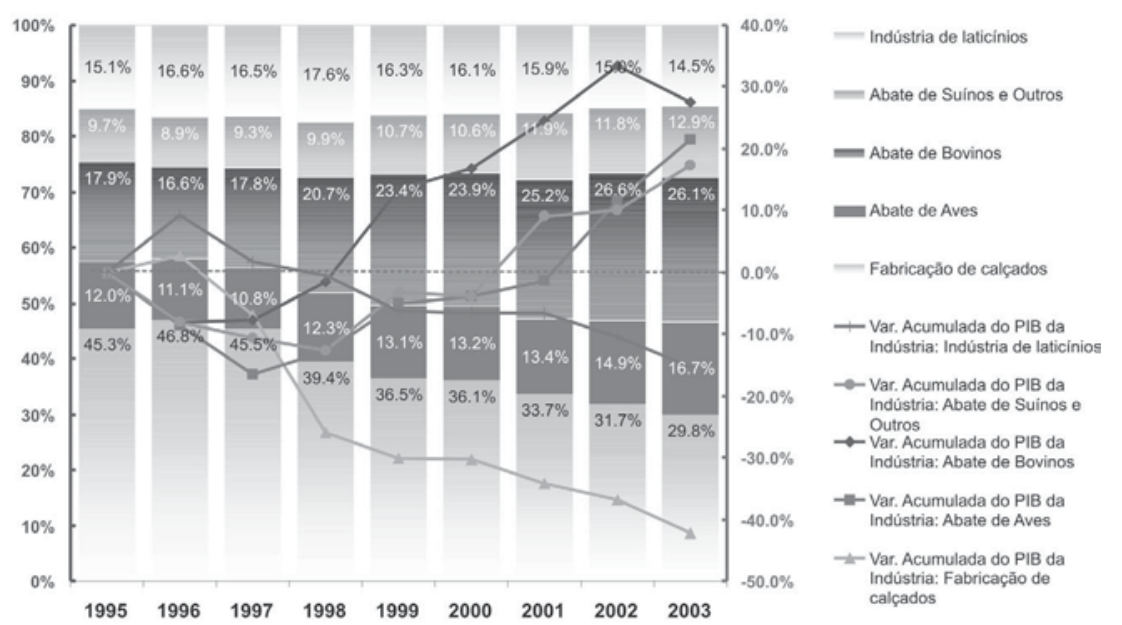

Fonte: dados da pesquisa 


\section{Conclusões}

O segmento familiar da agropecuária brasileira e as cadeias produtivas a ela interligadas responderam, em 2003, por 10,1\% do PIB brasileiro, o que equivale a $\mathrm{R} \$ 157$ bilhões em valores daquele ano. Tendo em vista que o conjunto do agronegócio nacional foi responsável, nesse ano, por 30,6\% do PIB, fica evidente o peso da agricultura familiar na geração de riqueza do país.

As estimativas do PIB do agronegócio familiar e sua evolução nos últimos oito anos (1995 a 2003) mostram, claramente, que os pequenos agricultores ou os agricultores familiares respondem por parcela expressiva da riqueza nacional, mesmo tendo em vista a insuficiência de terras, as dificuldades creditícias, o menor aporte tecnológico, a fragilidade da assistência técnica e a subutilização da mão-de-obra. Essa qualidade pujante decorre, por um lado, da existência de parcelas importantes do segmento familiar integradas aos setores agroindustriais e de distribuição e, de outro, à utilização plena de suas terras. Cabe destacar o quão importante são esses agricultores nas atividades da pecuária de pequeno porte - altamente articulada com os setores industriais, na fumicultura e no beneficiamento de produtos alimentares.

Pela estrutura de composição do PIB do complexo agrícola familiar e patronal e sua evolução recente, discriminadas pelos cultivos e subsetores industriais, salienta-se o crescimento vertiginoso da soja tanto no segmento familiar como no patronal. Em termos do PIB pecuário, nota-se a forte expressividade desempenhada no sistema patronal pela bovinocultura de corte e uma maior diversificação da produção no caso do familiar, na qual a avicultura e produção leiteira merecem destaque.

Concretamente, cerca de $1 / 3$ do agronegócio brasileiro é atribuído à produção agropecuária realizada pelos agricultores familiares, cabendo observar, ademais, que o desempenho recente da agropecuária familiar e do agronegócio a ela articulada vem sendo bastante positivo, superando, inclusive, as taxas de crescimento relativas ao segmento patronal. 


\section{Referências bibliográficas}

FURTUOSO, M.C.O., GUILHOTO, J.J.M. "Estimativa e Mensuração do Produto Interno Bruto do Agronegócio da Economia Brasileira, 1994 a 2000”. Revista Brasileira de Economia e Sociologia Rural. Vol 41, $N^{\circ} 4$, p. 803-827, 2003.

GUILHOTO, J.J.M.; SESSO FILHO U.A. Estimação da Matriz InsumoProduto a partir de Dados Preliminares das Contas Nacionais. Economia Aplicada. Vol. 9, № 2, 2005.

INSTITUTO BRASILEIRO DE GEOGRAFIA E ESTATÍSTICA - IBGE. Matriz Insumo-Produto: 1996. Site: http://www.ibge.gov.br (18 jul. 2005)

INSTITUTO BRASILEIRO DE GEOGRAFIA E ESTATÍSTICA - IBGE. Sistema de contas nacionais: Brasil: 1996-2003. Site: http://www.ibge.gov. br (02 ago. 2005)

INSTITUTO BRASILEIRO DE GEOGRAFIA E ESTATÍSTICA - IBGE. Sistema IBGE de recuperação automática - SIDRA: Brasil: 1997-2004. Site: http://www.ibge.gov.br (02 ago. 2005)

INSTITUTO NACIONAL DE COLONIZAÇÃO E REFORMA AGRÁRIA - INCRA. Novo retrato da agricultura familiar - o Brasil redescoberto. Projeto de Cooperação Técnica INCRA/FAO. Brasília. Fev, 2000. Site: http://www.incra.gov.br/fao/ (18 jul. 2005).

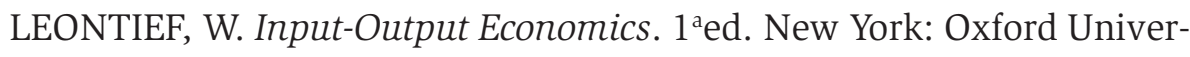
sity Press, 1986.

Recebido em setembro de 2005 e revisto em maio de 2006 